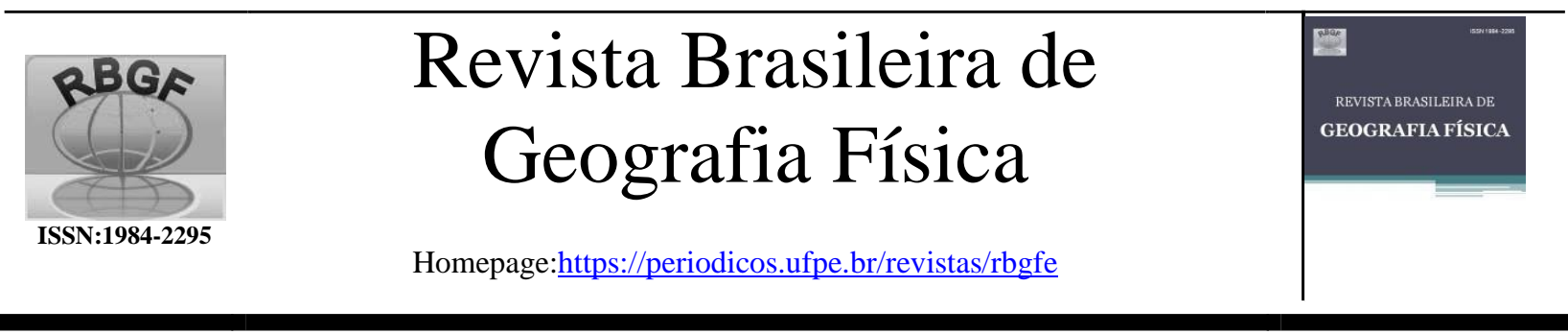

\title{
Parâmetros de Qualidade da Água no Brasil
}

\author{
Rodolfo Durante Serraglio ${ }^{1}$; Marta Aparecida de Moura ${ }^{2}$; Sérgio Marques Costa ${ }^{3}$; Alba Regina Azevedo Arana ${ }^{4}$; Maíra \\ Rodrigues Uliana ${ }^{5}$
}

${ }^{1}$ Mestre em Ciências Ambientais do Programa de Pós-Graduação em Meio Ambiente e Desenvolvimento Regional da Universidade do Oeste Paulista
- PPGMADRE/Unoeste - Campus II, Bloco B2, sala 206, Rodovia Raposo Tavares, km 572, Bairro do Limoeiro, Presidente Prudente-SP, CEP 19067-
175. E-mail: rodolfods15@ hotmail.com. ORCID:https://orcid.org/0000-0003-4160-5551. ${ }^{2}$ Doutoranda (bolsista CAPES), no Programa de Pós-
Graduação em Meio Ambiente e Desenvolvimento Regional da Universidade do Oeste Paulista - PPGMADRE/Unoeste, - Campus II, Bloco B2, sala
206, Rodovia Raposo Tavares, km 572, Bairro do Limoeiro, Presidente Prudente-SP, CEP 19067-175. E-mail: martaapmoura @ hotmail.com. ORCID:
https://orcid.org/0000-0002-0124-2883. ${ }^{3}$ Pesquisador (PNPD/CAPES) no Programa de Pós-Graduação em Meio Ambiente e Desenvolvimento
Regional da Universidade do Oeste Paulista - PPGMADRE/Unoeste. - Campus II, Bloco B2, sala 206, Rodovia Raposo Tavares, km 572, Bairro do
Limoeiro, Presidente Prudente-SP, CEP 19067-175. E-mail: marxcosta@ @mail.com. ORCID:http://orcid.org/0000-0001-9287-065X. ${ }^{4}$ Docente do
Programa de Pós-Graduação em Meio Ambiente e Desenvolvimento Regional da Universidade do Oeste Paulista - PPGMADRE/Unoeste - Campus
II, Bloco B2, sala 206, Rodovia Raposo Tavares, km 572, Bairro do Limoeiro, Presidente Prudente-SP, CEP 19067-175. E-mail: alba@ unoeste.br.
ORCID: http://orcid.org/0000-0001-8995-4449. ${ }^{5}$ Docente do Programa de Pós-Graduação em Meio Ambiente e Desenvolvimento Regional da
Universidade do Oeste Paulista - PPGMADRE/Unoeste - Campus II, Bloco B2, sala 206, Rodovia Raposo Tavares, km 572, Bairro do Limoeiro,
Presidente Prudente-SP, CEP 19067-175. E-mail: maira@ unoeste.br. ORCID:http://orcid.org/0000-0002-2794-0217(autora correspondente).
Artigo recebido em 15/04/2021 e aceite em 19/11/2021.

R E S U M O

Nos últimos anos a qualidade da água e do tratamento de esgoto no Brasil está em evidência e ampla discussão, devido aos diversos casos de contaminação por cianobactérias e agentes patógenos, dando destaque neste estudo: a Geosmina, o ZikaVirus e a COVID-19, que impactam os corpos hídricos. O objetivo deste pauta-se no debate da atual legislação e agências reguladoras que classificam a qualidade da água, interpretando critérios para a preservação da vida aquática, a conservação das áreas que circundam os rios e seus possíveis desdobramentos para a saúde humana. A metodologia está alicerçada na revisão literária em sites nacionais e internacionais, em órgãos e instituições públicas, definiu-se o IVA Índice da Preservação de Vida Aquática (CETESB, 2017a/b) como estratégico na preservação do ecossistema aquático e provendo água potável para o consumo humano. Constatou-se como resultados: A diversidade de 60 agências controladoras em todo o país desestimula uma centralidade de dados e controle. A ANA (2021) somente responsabilizase em analisar: pH, oxigênio dissolvido, condutividade e temperatura, sem dispositivos de controle para evitar contaminações, e em destaque: a CEDAE em repetidos episódios de contaminação por geosmina no Rio Guandu, que comprovama eutrofização deste corpo d'água e a má qualidade da água fornecida ao consumidor, evidenciada por odor e sabor desagradáveis.

Palavras-chave: IQA;qualidade de recursos hídricos;regulação hídrica; contaminação aquática.

\section{Water Quality Parameters in Brazil}

\begin{abstract}
A B S T R A C T
In recent years the quality of water and sewage treatment in Brazil is in evidence and widely discussed, due to the various cases of contamination by cyanobacteria and pathogens, giving prominence in this study: Geosmina, ZikaVirus and COVID-19, that impact water bodies. The purpose of this is to debate the current legislation and regulatory agencies that classify water quality, interpreting criteria for the preservation of aquatic life, the conservation of the areas that surround the rivers and their possible consequences for human health. The methodology was based on the literary review on national and international sites, in public bodies and institutions, the IVA - Aquatic Life Preservation Index (CETESB, $2017 \mathrm{a} / \mathrm{b}$ ) was defined as strategic for the preservation of the aquatic ecosystem and providing drinking water for human consumption. It was found as results: The diversity of 60 controlling agencies across the country discourage a centrality of data and control. ANA (2021) is only responsible for analyzing: pH, dissolved oxygen, conductivity and temperature, without control devices to avoid contamination, and highlighted: CEDAE in repeated episodes of geosmina contamination in the Guandu River, which prove eutrophication of this body of water and the poor quality of the water supplied to the consumer, unpleasant odor and taste.
\end{abstract}


Keywords: Water Quality Index; water resources quality; water regulation; aquatic contamination.

\section{Introdução}

Atualmente, a água é um recurso significativo para o crescimento socioeconômico e a proteção de ambientes saudáveis. Os recursos hídricos devidamente controlados são considerados uma parte vital do desenvolvimento de uma região, estando ligados inclusive com a redução dapobreza e desigualdades (Xiang et al., 2021; Luo et al., 2020).

Os recursos hídricos devem ser gerenciados de forma adequada, podendo ser utilizados para avaliar o impacto do meio ambiente, pois representam um desafio específico na concepção de sistemas ecológicos (Issii et al., 2020; Liraet al., 2020; Macias-Fauriaet al., 2020).

$\mathrm{O}$ desenvolvimento econômico e a complexidade dasorganizações da sociedade atual,podem causar alterações tanto no ciclo hidrológico, quanto na qualidade da água, afetando indiretamente o próprio ser humano, uma vez que osrecursos hídricos estão sujeitos à ação e imprudência antropogênica (da Silva et al., 2021, Silvaet al., 2020).

Assim, torna-se cada vez mais evidente a tendência mundial em se preservar os recursos naturais, seja através das legislações vigentes e/ou por decorrência de influência da população. McKinley et al. (2017) enfatizam quanto à demasiada escala e complexidade dos problemas ambientais que inserem substanciais desafios para a proteção ambiental e gestão dos recursos naturais. Desta forma, é inevitável que sejam realizados programas de recuperação ou renovação dos recursos naturais.

Bifano et al. (2020) trazem a discussão sobre o cenário de degradação dos recursos hídricos, evidenciados pelas dissonâncias $\mathrm{Na}$ qualidade da água dos rios, causadas principalmente pelos resísuos e efluentes despejados e uso e ocupação do solo desordenado. Desta forma, o monitoramento dos recursos hídricos, realizados através da avaliação da qualidade da água torna-se de extrema importância (Bifano et al., 2020; Oliveira et al., 2020).

Esta qualidade pode ser estimada por um conjunto de parâmetros, entre os quais citam-se a sua potabilidade, a segurança que apresenta para o ser humano e para o bem estar dos ecossistemas, podendo esta, apresentar variações com o decorrer do tempo (Ewaid et al., 2020; Rodríguez-Tito, Gómez-Luna, 2020; Richter; Netto, 2007).
A qualidade da água desempenha uma função importante na vida humana e nas caraterísticas de um ecossistema. Através da análise dos parâmetros físico-químicos e microbiológicos é possível mensurar a qualidade ambiental de uma bacia hidrográfica, e consequentemente de uma região(Pantojaet al., 2021; Oliveira et al., 2018).

Diante deste cenário, o trabalho questiona: Em que sentido a regulamentação dos recursos hídricos no Brasil é adequada para indicar a qualidade da água? A hipótese adotada neste trabalho é que somente a articulação entre as agencias reguladores de agua no Brasil poderá unificar dados contribuindo para monitoramento mais adequado da qualidade dos recursos hídricos.

Os critérios que avaliam a qualidade da água utilizados no Brasilsão complexos e normatizados por diversas agências reguladoras, em âmbito federal, estadual e intermunicipal e algumas vezes até municipal. Além disso, são variados os parâmetros e índices utilizados para esta avaliação de qualidade.Assim, o artigo tem como objetivo discutir e analisar os critérios e parâmetros utilizados pelas agências reguladoras que classificam a qualidade da água no Brasil, enfocando aspectos importantes para a manutenção da vida aquática, a conservação e preservação das áreas ambientalmente protegidas e os desdobramentos na saúde humana.

\section{Procedimentos Metodológicos}

O estudo trata-se de uma revisão literária, com viés descritivo, de característica qualiquantitativa, que aborda os parâmetros e legislações que permeiam a qualidade da água no Brasil. As bases de dados utilizados foram: Google Acadêmico, Scielo, PubMed, Elsevier, Science Direct, Springer, Repositórios (Dissertações e Teses) da: FGV, UnB, UNESC, Unesp, UFGRS, USP, Unioeste e Uniarp e órgãos estatais: ANA, FioCruz, D'Or, Embrapa, CAGECE, CETESB, CEDAE, COSAMA, Arce e Sanepar.

Optou-se pela análise do IVA - Índice da Preservação da Vida Aquática, conforme as diretrizes da CETESB (2017a/b).

Critérios de Análise da Qualidade da Água, Agências Reguladoras e suas Prestadoras de Serviçosno Brasil 
Atualmente diversos são os critérios que podem caracterizar a qualidade das águas (Passos et al., 2018). No Brasil, os padrões de qualidade são estabelecidos de acordo com a classificação dos cursos hídricos, por intermédio das definições de parâmetros numéricos ou qualitativos para os índices de qualidade, que definem a preservação das águas.

Os parâmetros e as diretrizes jurídicas fixadas pela legislação brasileira para definir os índices de qualidade da água, na maioria das vezes obedecem aos padrões internacionais. Tendo em vista que existe uma diferenciação entre as águas dos biomas nacionais com os cursos d'água internacionais, tal situação potencializa falhas nos dispositivos legais que regulamentam o tema.

De acordo com a Agência Nacional de Águas - ANA (2019), através do portal de qualidade das águas, avaliar e monitorar a qualidade das águas superficiais é de extrema importância para a gestão dos recursos hídricos, principalmente para orientar quanto aos diversos usos da bacia hidrográfica.

A legislação brasileira atualizou-se conforme o Novo Marco do Saneamento Básico Lei ${ }^{\circ} 14.026$, de 15 de julho de 2020, que busca atingir a meta de universalização, onde $99 \%$ da população brasileira tenha acesso à água potável e 90\% ao tratamento e coleta de esgoto até o ano de 2033 (Brasil, 2020).

Existem no Brasil por volta de 60 agências reguladoras de serviços de saneamento nas esferas: municipal, intermunicipal, distrital e/ou estadual, onde tais "[...] instituições regulam isolada ou conjuntamente os serviços de saneamento básico: abastecimento de água, coleta e tratamento de esgotos, manejo de resíduos sólidos e/ou drenagem urbana" (ANA, 2021, grifo nosso).

A Sanepar-Companhia de Saneamento do Paraná fundada da década de 1960 possui sede em Curitiba, tem características de uma sociedade de economia mista, de capital aberto e controlado pelo Estado (SANEPAR, 2019).

Em 1969, a COSAMA - Companhia de Saneamento do Amazonas - foi criada como uma empresa de economia mista, de regime jurídico privado como sociedade anônima, mas, atualmente dos 62 municípios que compõe o estado atende somente a 14 (COSAMA, 2021).

No estado de São Paulo, a Companhia de Tecnologia de Saneamento Ambiental (CETESB), desde 1974, mantém em operação a Rede de Monitoramento de Qualidade das Águas. Este programa tem por objetivo levantar informações sobre as condições reinantes nos principais rios e reservatórios do estado. Para isso, o Estado de São Paulo, foi dividido em 22 Unidades de Gerenciamento de Recursos Hídricos (UGRHIs) estruturadas no conceito de bacia hidrográfica, onde os recursos hídricos convergem para um corpo d'água principal (CETESB, 2018).

No Rio de Janeiro, a CEDAE - Companhia Estadual de Águas e Esgotos - foi constituída oficialmente em $1^{\circ}$ de agosto de 1975, de uma fusão entre a CEDAG - Empresa de Águas do Estado da Guanabara, ESAG - Empresa de Saneamento da Guanabara e da SANERJ Companhia de Saneamento do Estado do Rio de Janeiro (CEDAE, 2021a).

Já a ARCE - Agência Reguladora do Estado do Ceará, fiscaliza e monitora os serviços de abastecimento de água e esgotamento sanitário da CAGEGE - Companhia de Água e Esgoto do Ceará, conforme os termos da Resolução n ${ }^{\circ} 130$ de 25 de março de 2010 (ARCE, 2021).

Existe por parte da ANA a iniciativa de ordem federal no controle da qualidade da água, liderada pelo Programa Nacional de Avaliação da Qualidade das Águas - PNQA, que conta com 1.340 pontos em todo o território e avalia 4 parâmetros básicos: pH, oxigênio dissolvido, condutividade e temperatura (PNQA, 2021, grifo nosso).

Este aporte de argumentos evidencia a ausência de articulação entre agências controladoras e prestadoras de serviços sanitários, pois, não existe uma unificação nacional no padrão da qualidade das águas, o controle não estima a qualidade da vida aquática, muito menos as condições ambientaisno entorno, tanto como são escassas as ações de fiscalização e/ou autuações em casos de infrações.

\section{Índices de Caracterização da Qualidade da Água}

Devido à variedade de parâmetros a serem estudados, os Índices de Qualidade de Águas (IQA) atualmente utilizados pela CETESB podem ser interessantes no sentido de facilitar a compreensão dos resultados. As variáveis de qualidade, que fazem parte do cálculo do IQA, refletem, principalmente, a contaminação dos corpos hídricos ocasionada pelo lançamento de esgotos domésticos. O Índice do Estado Trófico (IET) tem por objetivo classificar corpos d'água em diferentes graus de trofia, ou seja, avalia a qualidade da água quanto ao enriquecimento por 
nutrientes e seu efeito relacionado ao crescimento excessivo das algas ou ao aumento da infestação de macrófitas aquáticas.

A partir do ano de 2002, a CETESB passou a utilizar índices diferenciados para cada forma de uso da água, por exemplo, Índice de Qualidade de Águas Brutas para Fins de Abastecimento Público (IAP), o Índice de Preservação da Vida Aquática (IVA) e o Índice de Balneabilidade (IB) (CETESB, 2017a).
O Quadro 01 exibe os índices de qualidade das águas anteriormente referenciados, com suas respectivas definições de acordo com a CETESB. Há de se destacar que ainda existem outros índices de qualidade da água, tanto apresentados pela CETESB quanto pela Agência Nacional das Águas (ANA).

Quadro 01. Indicadores de Qualidade da Água de acordo com a CETESB.

\begin{tabular}{|c|c|c|}
\hline ÍNDICES & DEFINIÇÕES & FONTE \\
\hline $\begin{array}{l}\text { IQA - Índice de } \\
\text { Qualidade das } \\
\text { Águas }\end{array}$ & $\begin{array}{l}\text { O IQA é um índice que foi adaptado pela CETESB a partir de } \\
\text { um estudo realizado na década de } 70 \text { pela "National } \\
\text { Sanitation Foundation" dos Estados Unidos. Este índice } \\
\text { utiliza-se de nove parâmetros para classificar a qualidade das } \\
\text { águas, principalmente com finalidade de abastecimento } \\
\text { público. }\end{array}$ & $\begin{array}{l}\text { CETESB } \\
(2017 a)\end{array}$ \\
\hline $\begin{array}{l}\text { IAP - Índice de } \\
\text { Qualidade das } \\
\text { Águas Brutas para } \\
\text { Fins de } \\
\text { Abastecimento } \\
\text { Público }\end{array}$ & $\begin{array}{l}\text { O IAP origina-se a partir dos resultados de } 2 \text { outros índices, o } \\
\text { IQA e o ISTO (Índice de Substâncias Tóxicas e } \\
\text { Organolépticas), que é formado pelo grupo de substâncias que } \\
\text { afetam a qualidade organoléptica da água. Este índice é } \\
\text { normalmente empregado em análises de rios ou reservatórios } \\
\text { destinados ao abastecimento público. }\end{array}$ & $\begin{array}{l}\text { CETESB } \\
(2017 a)\end{array}$ \\
\hline $\begin{array}{l}\text { IET - Índice do } \\
\text { Estado Trófico }\end{array}$ & $\begin{array}{l}\text { O IET é um índice que determina nos cursos d'água a } \\
\text { quantidade excessiva de algas e cianobactérias, classificando- } \\
\text { os em diferentes graus de trofia. Este índice é exigido para os } \\
\text { rios e reservatórios do Estado de São Paulo }\end{array}$ & $\begin{array}{l}\text { CETESB } \\
(2017 a)\end{array}$ \\
\hline $\begin{array}{l}\text { IB - Índice de } \\
\text { Balneabilidade }\end{array}$ & $\begin{array}{l}\text { O IB, aplicado em rios e reservatórios com praias de águas } \\
\text { interiores, avalia a qualidade das águas para fins de recreação } \\
\text { de contato primário. }\end{array}$ & $\begin{array}{l}\text { CETESB } \\
(2017 a)\end{array}$ \\
\hline $\begin{array}{l}\text { IVA - Índices de } \\
\text { Qualidade das } \\
\text { Águas para Proteção } \\
\text { da Vida Aquática e } \\
\text { de Comunidades } \\
\quad \text { Aquáticas }\end{array}$ & $\begin{array}{l}\text { O IVA avalia a qualidade das águas com a finalidade de } \\
\text { proteger a Fauna e a Flora de forma geral. Este índice leva em } \\
\text { consideração dois outros índices, o IPMCA - Índice de } \\
\text { Variáveis Mínimas para a Preservação da Vida Aquática e o } \\
\text { IET - Índice do Estado Trófico. Assim, o IVA fornece } \\
\text { informações sobre o grau de trofia dos corpos d'água } \\
\text { analisados, bem com fatores ecotoxicológicos. }\end{array}$ & $\begin{array}{l}\text { (Zagatto et al., } \\
1999 \text { apud } \\
\text { CETESB, } \\
\text { 2017a, p.12) }\end{array}$ \\
\hline
\end{tabular}

Fonte: Dados adaptados pelos Autores (2021 apud CETESB, 2017a).

Índice de Qualidade de Água para Proteção da Vida Aquática - IVA

Diferente dos índices que avaliam a qualidade da água para o consumo humano e recreação de contato primário, o IVA (Índice de Qualidade de Água para Proteção da Vida Aquática) tem a finalidade de avaliar as águas para fins de proteção da fauna e flora em geral.

Este índice leva em consideração a existência e a concentração de contaminantes químicos tóxicos, e duas das variáveis consideradas essenciais para a biota ( $\mathrm{pH}$ e oxigênio dissolvido). Estas variáveis são agrupadas no Índice de Variáveis Mínimas para a Preservação da Vida Aquática (IPMCA) e no Índice do Estado Trófico (IET) de Carlson modificado por Lamparelli (2004).

Assim, o IVA, através dos graus de ponderação (Tabela 1), além de fornecer informações sobre a qualidade da água em termos 
ecotoxicológicos, concebe também dados sobre o seu grau de trofia (Zagatto et al., 1999 apud CETESB, 2017a).

De acordo com a CETESB (2017a), o IVA é calculado da seguinte forma (eq. 01):

$\mathrm{IVA}=(\mathrm{IPMCA} \times 1,2)+\mathrm{IET} \quad$ eq. 01

Onde:

IPMCA - Índice de Variáveis Mínimas para a Preservação da Vida Aquática;

IET - Índice de Estado Trófico.

Tabela 01. Graus de Ponderação do IVA.

\begin{tabular}{cc}
\hline Categoria & Ponderação \\
\hline Ótima & IVA $\leq 2,5$ \\
Boa & $2,6 \leq \mathrm{IVA} \leq 3,3$ \\
Regular & $3,4 \leq \mathrm{IVA} \leq 4,5$ \\
Ruim & $4,6 \leq \mathrm{IVA} \leq 6,7$ \\
Péssima & $6,8 \leq \mathrm{IVA}$ \\
\hline
\end{tabular}

Fonte: Adaptado CETESB (2017a).

A partir da determinação do valor de ponderação do IVA é possível classificar o corpo d'água em relação à qualidade para a proteção da vida aquática.

De acordo com a CETESB (2017a), o IPMCA é composto por dois grupos de variáveis, o grupo de variáveis essenciais (1) e o grupo de substâncias tóxicas (2):

(1) O grupo de variáveis essenciais (oxigênio dissolvido, $\mathrm{pH}$ e toxicidade). Para cada variável incluída no IPMCA, são estabelecidos três diferentes níveis de qualidade, com ponderações numéricas de 1 a 3 e que correspondem a padrões de qualidade de água estabelecidos pela Resolução CONAMA $357 / 05$, e padrões preconizados pelas legislações americana (USEPA, 1991) e francesa (Code Permanent: Environnement et Nuisances, 1986), que estabelecem limites máximos permissíveis de substâncias químicas na água, com o propósito de evitar efeitos de toxicidade crônica e aguda à biota aquática.

(2) Grupo de substâncias tóxicas (cobre, zinco, chumbo, cromo, mercúrio, níquel, cádmio, surfactantes e fenóis). Neste grupo foram incluídas as variáveis que são atualmente avaliadas pela Rede de Monitoramento de Qualidade das Águas Interiores do Estado de São Paulo e que identificam o nível de contaminação por substâncias potencialmente danosas às comunidades aquáticas.
Esses níveis refletem as seguintes condições de qualidade de água. Nível A: Águas com características desejáveis para manter a sobrevivência e a reprodução dos organismos aquáticos. Atende aos padrões de qualidade da Resolução CONAMA 357/2005 para águas classes I e II - (ponderação 1). As exceções são o Oxigênio Dissolvido (OD) para classe I cujo valor é $=6,0$ mg.L ${ }^{-1} \mathrm{O}_{2}$ e os Fenóis Totais. Nível B: Águas com características desejáveis para a sobrevivência dos organismos aquáticos, porém a reprodução pode ser afetada a longo prazo (ponderação 2). Nível C: Águas com características que podem comprometer a sobrevivência dos organismos aquáticos (ponderação 3) (CETESB, 2017a).

Com a finalidade de melhor entendimento, segue a Tabela 02 que define os grupos (Variáveis Essenciais e Substâncias Tóxicas), os tipos de variáveis, os níveis, a faixa de variação de concentração (valor obtido após análise laboratorial) e o grau de ponderação, para que assim, seja possível a classificação do IPMCA.

Dadas as ponderações para as variáveis determinadas em uma amostra de água, o IPMCA é calculado através da seguinte equação 02 :

$\mathrm{IPMCA}=\mathrm{VE} \times \mathrm{ST} \quad$ eq. 02

Onde:

VE: Valor da maior ponderação do grupo de variáveis essenciais;

ST: Valor médio das três maiores ponderações do grupo de substâncias tóxicas. Este valor é um número inteiro e o critério de arredondamento deverá ser o seguinte: valores menores que 0,5 serão arredondados para baixo e valores maiores ou iguais a 0,5 para cima (CETESB, 2017a).

O valor do IPMCA pode variar de 1 a 9 , sendo subdividido em quatro faixas de qualidade, classificando as águas para proteção da vida aquática, conforme a Tabela 03.

Além dos índices comumente utilizados para caracterizar a qualidade dos recursos hídricos, outro índice que permite estimar a qualidade da água é o IET - Índice de Estado Trófico (Rodríguez-Tito, Gómez-Luna, 2020; Oliveira et al., 2018).

O IET (Índice do Estado Trófico) é o segundo índice que compõe o IVA, e tem por objetivo classificar os corpos d'água em diferentes graus de trofia, ou seja, avalia a qualidade da água quanto ao enriquecimento por nutrientes e seus efeitos relacionados ao crescimento excessivo das 
algas, ou ao aumento da infestação de macrófitas aquáticas, diminuição na concentração do oxigênio dissolvido e aumento das populações de cianobactérias.

Quanto à eutrofização, Lamparelli (2004, p.7, grifo nosso) define esse processo como: o enriquecimento de um corpo d'água por nutrientes sejam por processo natural ou provocado pelo homem, os principais poluentes responsáveis pela eutrofização das águas: o fósforo e o nitrogênio, geralmente presentes em fertilizantes agrícolas, esgotos industriais e domésticos.

O processo de eutrofização natural ocorre de forma lenta e contínua. Sem a interferência humana, as chuvas trazem uma série de nutrientes para os cursos d'água, oslagos que antes possuíam altas profundidades, por um processo de assoreamento, tornaram-serasos, aumentando a atividade biológica e a concentração de nutrientes (Rocha, 2021; Human et al., 2018).

Com o aumento da população nas zonas urbanas elevou-se também a demanda por alimentos, aliado a isto, ocorreu à necessidade de ampliar às produções agrícolas. De acordo com Pantano et al. (2016), a expansão do setor exigiu intensivo processo de mecanização agrícola e maior uso de fertilizantes nas lavouras para auxílio no aumento da produtividade.

Neste viés analítico, os processos de eutrofização em rios podem ser definidos:

O nitrogênio e o fósforo presentes nos rios e lagos são nutrientes de grande importância à cadeia alimentar, entretanto, quando descarregados em altas concentrações em águas superficiais e associados às boas condições de luminosidade provocam o enriquecimento do meio, fenômeno este denominado eutrofização. Segundo Smith \&Schindler (2009), a eutrofização pode levar à alteração no sabor, no odor, na turbidez e na cor da água, à redução do oxigênio dissolvido, provocando crescimento excessivo de plantas aquáticas, mortandade de peixes e outras espécies aquáticas, além do comprometimento das condições mínimas para o lazer na água (Barreto et al., 2013, p. 2166).

Práticas inadequadas relacionadas ao uso e ocupação das bacias agem como fontes de poluição para os corpos d'água. Estas, somadas as características naturais das bacias, podemprovocar aumento nos teores de nutrientes, podendo indicar eutrofização nos ambientes aquáticos. Desta forma, entender as consequências das alterações na dinâmica dos mananciais é de suma importância para o gerenciamento dos recursos hídricos e preservação da água (Rocha, 2021).

Assim, chega-se à interpretação do Quadro 02, o qual define as categorias de estado trófico de um corpo de água e suas características conforme as subdivisões em relação às classificações básicas.

Para a classificação dos corpos d'água quanto ao estado de trofia é necessário a realização do cálculo do índice de eutrofização, na qual são utilizadas duas variáveis: clorofila $a$ e fósforo total. De acordo com a CETESB (2017a, p.10) esses dois parâmetros são satisfatórios para a determinação do IET, visto que:

Nesse índice, os resultados correspondentes ao fósforo, IET (P), devem ser entendidos como uma medida do potencial de eutrofização, já que este nutriente atua como o agente causador do processo. A avaliação correspondente à clorofila a, IET (CL), por sua vez, deve ser considerada como uma medida da resposta do corpo hídrico ao agente causador, indicando de forma adequada o nível de crescimento de algas que tem lugar em suas águas. Assim, o índice médio engloba, de forma satisfatória, a causa e o efeito do processo (CETESB, 2017a, p.10). 
Tabela 02. Variáveis componentes do IPMCA.

\begin{tabular}{|c|c|c|c|c|}
\hline Grupos & Variáveis & Níveis & Faixa de variação & Ponderação \\
\hline \multirow{9}{*}{$\begin{array}{c}\text { Variáveis } \\
\text { Essenciais } \\
\quad(\mathrm{VE})\end{array}$} & \multirow{3}{*}{ OD $\left(\mathbf{m g} \cdot \mathbf{L}^{-1}\right)$} & $\mathrm{A}$ & $\geq 5$ & 1 \\
\hline & & $\mathrm{B}$ & 3 a 5 & 2 \\
\hline & & $\mathrm{C}$ & $<3$ & 3 \\
\hline & \multirow{3}{*}{ pH } & $\mathrm{A}$ & 6 a 9 & 1 \\
\hline & & $\mathrm{B}$ & $5 a<6 e>9 a 9,5$ & 2 \\
\hline & & $\mathrm{C}$ & $<5 \mathrm{e}>9,5$ & 3 \\
\hline & \multirow{3}{*}{ Toxicidade } & $\mathrm{A}$ & Não tóxico & 1 \\
\hline & & $\mathrm{B}$ & Efeito crônico & 2 \\
\hline & & $\mathrm{C}$ & Efeito agudo & 3 \\
\hline \multirow{27}{*}{$\begin{array}{l}\text { Substâncias } \\
\text { Tóxicas } \\
\text { (ST) }\end{array}$} & \multirow{3}{*}{ Cádmio (mg.L ${ }^{-1}$ ) } & $\mathrm{A}$ & $\leq 0,001$ & 1 \\
\hline & & $\mathrm{B}$ & $>0,001$ a 0,005 & 2 \\
\hline & & $\mathrm{C}$ & $>0,005$ & 3 \\
\hline & \multirow{3}{*}{$\begin{array}{c}\text { Cromo } \\
\left(\text { mg.L }{ }^{-1}\right)\end{array}$} & $\mathrm{A}$ & $\leq 0,05$ & 1 \\
\hline & & $\mathrm{B}$ & $>0,05$ a 1 & 2 \\
\hline & & $\mathrm{C}$ & $>1$ & 3 \\
\hline & \multirow{3}{*}{$\begin{array}{c}\text { Cobre } \\
\left(\mathbf{m g} . \mathrm{L}^{-1}\right)\end{array}$} & $\mathrm{A}$ & $\leq 0,02$ & 1 \\
\hline & & $\mathrm{B}$ & $>0,02$ a 0,05 & 2 \\
\hline & & $\mathrm{C}$ & $>0,05$ & 3 \\
\hline & \multirow{3}{*}{$\begin{array}{l}\text { Chumbo } \\
\left(\text { mg. }^{-1}\right)\end{array}$} & A & $\leq 0,03$ & 1 \\
\hline & & $\mathrm{B}$ & $>0,03$ a 0,08 & 2 \\
\hline & & $\mathrm{C}$ & $>0,08$ & 3 \\
\hline & \multirow{3}{*}{$\begin{array}{l}\text { Mercúrio } \\
\left(\text { mg.L }{ }^{-1}\right)\end{array}$} & $\mathrm{A}$ & $\leq 0,0002$ & 1 \\
\hline & & $\mathrm{B}$ & $>0,002$ a 0,001 & 2 \\
\hline & & $\mathrm{C}$ & $>0,001$ & 3 \\
\hline & \multirow{3}{*}{$\begin{array}{l}\text { Níquel } \\
\left(\mathbf{m g . L} \mathbf{L}^{-1}\right)\end{array}$} & $\mathrm{A}$ & $\leq 0,025$ & 1 \\
\hline & & $\mathrm{B}$ & $>0,025$ a 0,160 & 2 \\
\hline & & $\mathrm{C}$ & $>0,160$ & 3 \\
\hline & \multirow{3}{*}{$\begin{array}{l}\text { Fenóis } \\
\left(\text { mg.L } L^{-1}\right)\end{array}$} & $\mathrm{A}$ & $\leq 0,001$ & 1 \\
\hline & & $\mathrm{B}$ & $>0,001$ a 0,050 & 2 \\
\hline & & $\mathrm{C}$ & $>0,050$ & 3 \\
\hline & \multirow{3}{*}{$\begin{array}{l}\text { Surfactantes } \\
\left(\mathbf{m g} . \mathrm{L}^{-1}\right)\end{array}$} & $\mathrm{A}$ & $\leq 0,5$ & 1 \\
\hline & & $\mathrm{B}$ & $>0,5$ a 1 & 2 \\
\hline & & $\mathrm{C}$ & $>1$ & 3 \\
\hline & \multirow{3}{*}{$\begin{array}{c}\text { Zinco } \\
\left(\mathbf{m g . L} \mathrm{L}^{-1}\right)\end{array}$} & $\mathrm{A}$ & $\leq 0,18$ & 1 \\
\hline & & $\mathrm{B}$ & $>0,18$ a 1 & 2 \\
\hline & & $\mathrm{C}$ & $>1$ & 3 \\
\hline
\end{tabular}

Fonte: Adaptado de CETESB (2017a).

Tabela 03. Graus de Ponderação do IPMCA.

\begin{tabular}{cc}
\hline Categoria & Ponderação \\
\hline Boa & 1 \\
Regular & 2 \\
Ruim & $3 \mathrm{e} 4$ \\
Péssima & $\geq 6$ \\
\hline
\end{tabular}

Fonte: Adaptado de CETESB (2017a). 
Portanto, para o cálculo do IET são levados em consideração dois parâmetros: a) clorofila $a$ e b) fósforo total. As equações utilizadas para calcular o IET em rios, segundo a CETESB, modificado por Lamparelli (2004) estão apresentadas nas equações 3 e 4 :

IET $(C L)=10 x(6-((-0,7-0,6 x(\ln C L)) / \ln 2))-20$ eq. 3
IET $(P T)=10 x(6-((0,42-0,36 x(\ln P T)) / \ln 2))-20 \quad$ eq. 4

Onde:
PT: concentração de fósforo total medida à superfície da água, em $\mu \mathrm{g} . \mathrm{L}-1$;

CL: concentração de clorofila $a$ medida à superfície da água, em $\mu$ g.L-1;

$\ln$ : logaritmo natural.

O IET final, correspondente a esses dois parâmetros, é calculado através da média aritmética simples por meio da equação 5 :

$\operatorname{IET}=[\operatorname{IET}(\mathrm{PT})+\operatorname{IET}(\mathrm{CL})] / 2$ eq. 5

Quadro 02. Classificação do Estado Trófico dos Cursos d'água.

\begin{tabular}{|c|c|c|}
\hline Estado Trófico & $\begin{array}{c}\text { Características dos Corpos de } \\
\text { Água }\end{array}$ & Referência \\
\hline Ultraoligotrófico & $\begin{array}{lcc}\text { Produtividade } & \text { muito } & \text { baixa } \\
\text { concentração } & \text { de } & \text { nutrientes } \\
\text { insignificante, podem não originar } \\
\text { prejuízos aos usos da água. }\end{array}$ & Barreto et al. (2013) \\
\hline Oligotrófico & $\begin{array}{l}\text { Ambiente com baixa produtividade } \\
\text { biológica e baixa concentração de } \\
\text { nutrientes. }\end{array}$ & Braga $(2005$, p.97) \\
\hline Mesotrófico & $\begin{array}{l}\text { Características intermediárias em } \\
\text { relação aos oligotróficos e eutróficos. }\end{array}$ & Braga (2005, p.97) \\
\hline Eutrófico & $\begin{array}{l}\text { Produção vegetal excessiva e alta } \\
\text { concentração de nutrientes. }\end{array}$ & Braga $(2005$, p.97) \\
\hline Supereutrófico & $\begin{array}{l}\text { Alta produtividade nos corpos d'água, } \\
\text { baixa transparência, normalmente } \\
\text { afetados por ações antrópicas, floração } \\
\text { de algas e interferências nos seus usos } \\
\text { múltiplos. }\end{array}$ & Barreto et al. (2013) \\
\hline Hipereutrófico & $\begin{array}{l}\text { Elevada concentração de matéria } \\
\text { orgânica e } \\
\text { comprometimento acentuado quanto a } \\
\text { utilização, floração de algas, } \\
\text { mortandade de peixes e consequências } \\
\text { indesejáveis quanto aos seus usos } \\
\text { múltiplos. }\end{array}$ & Barreto et al. (2013) \\
\hline
\end{tabular}

Para corpos d'água onde o processo de eutrofização esteja devidamente estabelecido, os estados tróficos determinados pelos índices da clorofila $a$ e do fósforo, possivelmente coincidirão. Já, para locais onde existam variações de fatores ambientais, como a temperatura da água ou a alta turbidez, por exemplo, o índice relativo à clorofila $a$ irá refletir esse fato, classificando o estado trófico em um nível de menor trofia àquele determinado pelo índice do fósforo (CETESB, 2017a).
De forma a qualificar o corpo hídrico em graus de eutrofização, a CETESB utiliza-se do Îndice de Estado Trófico (IET). Portanto, a CETESB calcula o IET conforme os dados apontados pela Tabela 04, nesta são apresentados os limites de cada nível de trofia para rios.

Calculado o valor do IET (eq. 4), é possível verificar na Tabela 04 o nível trófico em que o curso d'água está classificado. A partir desta determinação constata-se, pela Tabela 05 , o valor 
atribuído à ponderação de acordo com a classificação do IET.

$\mathrm{O}$ coeficiente de ponderação identificado através da classificação do IET, junto ao coeficiente de ponderação do IPMCA será utilizado para determinar o valor do IVA.

\section{Análise dos Parâmetros da Água}

A determinação do Índice de Qualidade da Água para Preservação da Vida Aquática é realizada através da análise de um conjunto de parâmetros, sendo estes: oxigênio dissolvido, potencial hidrogeniônico, toxicidade, clorofila $a$ fósforo total, surfactantes, fenóis, cádmio, chumbo, cobre, cromo, mercúrio, níquel e zinco. A seguir serão descritas as principais características de cada parâmetro:

Oxigênio Dissolvido (OD): O oxigênio dissolvido em água é um parâmetro de muita importância para observar a qualidade de águas naturais e a sobrevivência dos organismos aeróbicos, este índice avalia a saúde do ecossistema aquático, onde, pouca quantidade de OD indica problemas na organização do sistema (Mendonçaet al., 2020; Figur; Reis, 2017).

De acordo com a Resolução CONAMA 357/05 a quantidade mínima de OD para a preservação da vida aquática, é de $4,0 \mathrm{mg} . \mathrm{L}^{-1}$, porém, existe variação de tolerância de espécie para espécie (Brasil, 2005).

Potencial hidrogeniônico (pH): a identificação da concentração de hidrogênio iônico na água é de extrema utilidade, pois fornecem variadas informações a respeito da qualidade da água, além disso, parâmetros simples e rápidos são extremaente importante para uma avaliação de qualidade acessível (Chen et al., 2020; Silva e Araújo, 2017).

$\mathrm{O} \mathrm{pH}$ encontrado nos córregos pode afetar direta ou indiretamente a fisiologia das espécies, visto que, o valor mensurado por meio de análises influencia em muitas reações químicas. $\mathrm{O}$ valor deste parâmetro normalmente é alterado por ação natural ou antrópica (deposição de reagentes em cursos d'água ou poluições atmosféricas) (Ulgenes et al., 2020; Braga et al., 2005).

Toxicidade: De acordo com CETESB (2017a) a toxicidade dos corpos d'água está associada aos efeitos e concentrações de contaminantes químicos tóxicos sobre os organismos aquáticos.

A avaliação da toxicidade das águas deve ser realizada através de ensaios ecotoxicológicos agudos, que consistem em cultivo dos organismos e os bioensaios com alguns espécies animais bioindicadoras, tais com Daphnia similis (Crustacea, Cladocera) e Danio rerio (Pisces, Cyprinidae) (Costa e Roche, 2020).

Clorofila $a$ : $\mathrm{O}$ aumento da concentração de clorofila $a$ está associada à maior quantidade de nutrientes eutrofizantes na água. Quanto maior a quantidade de nutrientes e a incidência de luz solar, maior será o crescimento da biomassa fitoplanctônica. Para locais onde a turbidez da água esteja elevada, impedindo a passagem de luz, menor será a produtividade primária das algas e consequentemente a concentração de clorofila $a$ (Da Silva Júnior et al., 2020;Cullen, 1982).

A detecção desta classe de compostos é importante para o monitoramento da qualidade da água, podem fornecer subsídios de gestão do meio ambiente e dos recursos hídricos em grandes áreas (Serbeto et al., 2021; Da Silva Júnior et al., 2020)

Fósforo total $(\mathbf{P t})$ : O fósforo está presente nas águas através das descargas de esgotos sanitários, constituído principalmente por matéria orgânica fecal e detergente em pó utilizados em larga escala domesticamente. É encontrado em grande quantidade em alguns efluentes industriais, como: fertilizantes, pesticidas, químicas em geral, conservas alimentícias, abatedouros, frigoríficos e laticínios. As águas drenadas tanto em áreas agrícolas quanto urbanas podem provocar a presença excessiva de fósforo em águas naturais (Chen et al., 2020; Hong et al., 2020; CETESB, 2017b).

A presença desse nutriente em excesso pode levar à eutrofização dos recursos hídricos, podendo causar diversos problemas ambientais associados a tais fenômenos (Rocha, 2021; Serbeto et al., 2021; Da Silva Júnior et al., 2020;).

Surfactantes: Os surfactantes são produtos químicos utilizados em elevadas proporções em inúmeras atividades domésticas e industriais, são também conhecidos como elementos tensoativos. Estes elementos são mundialmente utilizados em grandes quantidades como ingredientes ativos de detergentes domésticos e industriais, além de, produtos farmacêuticos, tintas e vernizes, plásticos, alimentos e agrotóxicos. O lançamento de efluentes que contém esses compostos nos cursos d'água podem ser prejudiciais à vida aquática (Freeling $e t$ al., 2019; Li et al., 2018).

Fenóis: Para os microrganismos, organismos aquáticos e para o ser humano, estes 
efluentes de origem industrial ou sanitária em grandes concentrações podem ser tóxicos. Tanto na Legislação Estadual (Artigo 18 do Decreto Estadual n. ${ }^{\circ}$ 8.468/76, São Paulo, 1976) quanto Federal (Artigo 16 da Resolução n. ${ }^{\circ} 430 / 11$ do CONAMA, Brasil, 2011), para as águas naturais, os padrões dos compostos fenólicos é bastante restritivo, 0,5 mg. $\mathrm{L}^{-1}$. Em águas tratadas os fenóis, por meio de reações químicas com cloro livre, formam os clorofenóis, e produzem sabor e odor na água (CETESB, 2017b).

Os fenóis podem ser uma ameaça significativa ao meio ambiente, visto que, podem apresentar efeitos altamente tóxicos e bioacumulativos sobre os organismos aquáticos. Além disso, apresentam alta solubilidade em água, permitindo assim que estes se mantenham em elevadas concentrações nos ambientes aquáticos (Singh et al. 2020; Wei et al., 2016).

Metais: devido ao desenvolvimento da urbanização e industrialização, o problema da poluição por metais tóxicos tornou-se um sério dilema ambiental. Esses metais não só têm grandes impactos nos organismos aquáticos, mas também ameaçam seriamente a saúde humana. Alguns metais tóxicos, como $\mathrm{Ni}$, , Cr, $\mathrm{Zn}, \mathrm{Cu}, \mathrm{Cde} \mathrm{Pb}$, têm potencial para causar sérios danos ambientais. As formas iônicas de $\mathrm{Cd}^{2+}, \mathrm{Pb}^{2+}$, e $\mathrm{Hg}^{2+}$, em especial, formam compostos extramamente tóxicos (Hong et al., 2020).

Cádmio (Cd): O cádmio é um metal que normalmente é liberado ao ambiente por efluentes industriais, sendo os principais segmentos: resíduos industriais de galvanoplastias, acessórios fotográficos, equipamentos eletrônicos, lubrificantes, pigmentos de solda e fertilizantes. Para águas não poluídas, a concentração máxima permitida é de $1 \mu \mathrm{g} . \mathrm{L}^{-1}$ (CETESB, 2017b).

O cádmio presente nos gases ou no solo, originados através processos industriais, normalmente são lixiviados para os corpos d'água em decorrência do escoamento superficial produzidos pela ação das chuvas. Este metal é considerado tóxico e com efeitos bioacumulativos sobre os organismos, mesmo que em pequenas quantidades (Hong et al., 2020; Lucon et al., 2020).
Chumbo (Pb): O chumbo é um elemento que tem ampla utilização em diversos seguimentos industriais, como a fabricação de esmalte, inseticidas, vidros, ligas metálicas, tintas e fabricação de baterias. $\mathrm{Na}$ água normalmente ocorre pela deposição atmosférica ou lixiviação do solo (CETESB, 2017b).

O chumbo é um dos metais tóxicos que em ambiente aquático pode induzir o acúmulo de substancias nocivo em tecidos específicos de animais aquáticos (Hong et al., 2020; Kim; Kang, 2017). A assimilação de metais poluentes em animais aquáticos pode estarrelacionada aos tipos de metais, espécies de peixes e tecidos e a química da água (Hong et al., 2020; Rajeshkumar e Li, 2018).

Cobre (Cu): Este elemento é normalmente utilizado em atividades de fundição e incineração, e principalmente na agricultura como algicida, pesticida, fungicida, entre outros. Se utilizado de forma descontrolada pode ser lixiviado para os córregos e lençol freático (CETESB, 2017b), podendo gerar impactos nos organismos aquáticos e ameaçando a saúde humana (Hong et al., 2020).

Cromo (Cr): O cromo em sua forma natural está presente no meio ambiente por determinados minerais e materiais vulcânicos, quando em formato hexavalente, geralmente ocorre por processos industriais (Oliveira et al., 2017).

Este metal se lançado em corpos d'água em quantidades elevadas e sem tratamento adequado pode ser prejudicial à biota aquática e à saúde humana (Hong et al., 2020; Aslam e Yousafzai, 2017).

Mercúrio (Hg): O mercúrio é um metal muito utilizado nos garimpos para a extração do ouro, além disto, é empregado também na produção de amalgamas, equipamentos elétricos, matéria-prima para compostos de mercúrio, entre outros (CETESB, 2017b).

É um elemento que pode ser prejudicial ao ambiente aquático, devido ás propriedades de bioacumulação em organismos, principalmente através de cadeias alimentares, sua forma iônicas forma compostos altamente tóxicos (Hong et al., 2020; Feng et al., 2018). 
Tabela 04. Classificação do Estado Trófico para rios segundo Índice de Carlson Modificado.

\begin{tabular}{cccc}
\hline $\begin{array}{c}\text { Categoria } \\
\text { (nível trófico) }\end{array}$ & Ponderação & P-total $\left(\mathbf{m g . m ^ { - 3 }}\right)$ & Clorofila $\boldsymbol{a}\left(\mathbf{m g} \cdot \mathbf{m}^{-\mathbf{3}}\right)$ \\
\hline Ultraoligotrófico & $\mathrm{IET} \leq 47$ & $\mathrm{P} \leq 13$ & $\mathrm{CL} \leq 0,74$ \\
Oligotrófico & $47<\mathrm{IET} \leq 52$ & $13<\mathrm{P} \leq 35$ & $0,74<\mathrm{CL} \leq 1,31$ \\
Mesotrófico & $52<\mathrm{IET} \leq 59$ & $35<\mathrm{P} \leq 137$ & $1,31<\mathrm{CL} \leq 2,96$ \\
Eutrófico & $59<\mathrm{IET} \leq 63$ & $137<\mathrm{P} \leq 296$ & $2,96<\mathrm{CL} \leq 4,70$ \\
Supereutrófico & $63<\mathrm{IET} \leq 67$ & $296<\mathrm{P} \leq 640$ & $4,70<\mathrm{CL} \leq, 46$ \\
Hipereutrófico & $\mathrm{IET}>67$ & $640<\mathrm{P}$ & $7,46<\mathrm{CL}$ \\
\hline
\end{tabular}

Fonte: Adaptado CETESB (2017a).

Tabela 05. Classificação do Índice de Estado Trófico - IET.

\begin{tabular}{cc}
\hline Categoria (Estado Trófico) & Ponderação \\
\hline Ultraoligotrófico & 0,5 \\
Oligotrófico & 1 \\
Mesotrófico & 2 \\
Eutrófico & 3 \\
Supereutrófico & 4 \\
Hipereutrófico & 5 \\
\hline
\end{tabular}

Fonte: Adaptado CETESB (2017a).

Níquel (Ni): Usualmente, o níquel é um metal utilizado na produção de moedas, pigmentos, aço inoxidável, manufaturas de baterias, entre outros. No meio aquático ele pode precipitar nas brânquias dos peixes e os matar por asfixia, além de ser tóxico, quando presente em soluções de $\mathrm{pH}$ baixo (Hong et al., 2020; CETESB, 2017b Apêndice E).

Zinco (Zn): É um metal utilizado na fabricação de xampus, desodorantes, protetores solares, suplementos vitamínicos, galvanização do aço, borrachas com pigmentos brancos, entre outros. Para os animais, a falta do zinco pode levar ao atraso no crescimento, entretanto seu excesso pode ser teratogênico, e em condições ambientais com altas concentrações, sua ingestão de quantidades excessivas pode levar a efeitos de envenenamento com possíveis consequências graves (Hong et al., 2020; CETESB, 2017b Apêndice E).

As concentrações de zinco no meio aquático podem estar associadas a processos naturais ou atividades antrópicas, tais como: drenagem de minas, resíduos industriais e municipais, escoamento urbano, erosões no solo e queima de resíduos (Noulas et al., 2018).

A problemática sanitária no Brasil: a contaminação nas águas e esgotos
Diversos estudos apontam que a problemática sanitária da contaminação das águas e esgotos no Brasil está cada vez mais recorrente. Assalie e Machado (2018, p.155) consolidam os estudos do Instituto Trata Brasil e Conselho Empresarial Brasileiro para o Desenvolvimento Sustentável - CEBDS, onde o Brasil ocupa $112^{\mathrm{a}}$ posição, num ranking de 200 países sobre saneamento básico, tal ranking utiliza o Índice de Desenvolvimento do Saneamento do Programa das Nações Unidas para o Desenvolvimento - Pnud entre os anos de 2001 e 2011.

Segundo o Instituto Trata Brasil (2021), o SNIS - Sistema Nacional de Informações sobre Saneamento, no ano de 2019, aponta que 54,1\% da população tem acesso à coleta de esgoto, $49,1 \%$ esgoto tratado, $83,7 \%$ tem acesso à água tratada, mas, ainda existem mais de 33 milhões de pessoas sem acesso à água potável.

No Brasil, as tecnologias que englobam os "serviços de saneamento básico" são: abastecimento de água, esgotamento sanitário, drenagem de águas pluviais, coleta e tratamento de resíduos sólidos e tratamento de águas residuárias (Dantas et al., 2012, p.274). O tratamento da água passa por diversas etapas que exigem controle do produtos químicos utilizados e também um acompanhamento dos padrões de qualidade, são elas: Pré-cloração; Pré-alcalinização; Coagulação; 
Floculação; Decantação; Filtração; Pósalcalinização; Desinfecção; Fluoretação (CAESB, 2021a; SABESP, 2021a). Já o tratamento de esgoto tem o objetivo de remover os poluentes do efluente através de processos físicos, químicos e/ou biológicos. O tratamento envolve a aplicação de microrganismos aeróbiocs que crescem, desenvolvem-se, formam flocos, que continuamente são recirculados junto ao efluente doméstico ou industrial, que contém matéria orgânica. Assim, o esgoto bruto e o loso ativado são misturados, agitados e aeradados ininterruptamente. Em seguida, o efluente é decantado, partes sólida e líquidasão separadas. A parte sedimentada volta ao processo (CAESB, 2021b; SABESP, 2021b). Assim, muitas outras substâncias tóxicas, tais como: agrotóxicos, medicamentos, resíduos industriais, entre outros não são tratados e diariamente contaminam esgotos e águas prejudicando a vida aquática, o ambiente em torno e possivelmente ocasionando problemas de saúde nos consumidores.

Estudos do Instituto D'Or de Pesquisa e Ensino - IDOR, da Fundação Oswaldo Cruz Fiocruz, da Universidade Federal do Rio de Janeiro - UFRJ e Universidade Federal Rural de Pernambuco - UFRPE, chegaram às conclusões que: "A presençade toxinas na água consumida pela população nordestina contribuiu para aumentar o número de casos de microcefalia associados à epidemia do vírus zika na Região Nordeste principalmente nos anos de 2015 e 2016" (AGÊNCIA BRASIL, 2020a, grifo nosso).

A água contaminada com saxitoxina proporcionou maior vulnerabilidade a uma determinada população do Nordeste, que infectada pelo vírus Zika, ocasionou o nascimento de crianças com malformações graves no sistema nervoso, relacionando a maior frequência que casos de microcefalia nesta região. Segundo o Ministério da Saúde, nos anos de 2015 a 2019 foram constatados 2.192 casos de microcefalia e outras malformações congênitas pelo vírus Zika na Região Nordeste, correspondendo a $62,5 \%$ dos casos no país, no Sudeste foram registrados 709 casos, equivalendo a 20,2\% (Agência Brasil, 2020a).

Na cidade do Rio de Janeiro as sucessivas contaminações denotam a presença de geosmina nas águas de consumo humano, assim, Smiderle et al. (2020, p.34) destacam:
Embora a crise no abastecimento de água da RMRJ tenha atingido a população repentinamente, não se pode dizer que essa foi uma "tragédia" totalmente desavisada; há décadas se reconhece que o sistema de abastecimento de água da região é frágil e que em grande medida isso se deve à poluição dos rios afluentes ao Guandu, principal manancial da região. Essa poluição é reflexo dos baixíssimos índices de coleta e tratamento de esgotos verificados nos municípios que circundam os afluentes ao Guandu [...] (Capodeferro e Tardin, 2020, p.34).

A própria CEDAE (2021b) em comunicado oficial de 06 de fevereiro reconheceu outro episódio da presença de geomisna na água, notando que o quantitativo de algas na lagoa próxima à estação de tratamento vem crescendo nos últimos dias, assim, a CEDAE comprometeuse a realização do protocolo operacional das barragens e interrompendo as atividades da ETA Guandu entre as 18/19h até às 5 h da manhã de 07 de fevereiro, objetivando diminuir o crescimento exponencial das algas e a ocorrência de geomisna no local. Além disso, diversos pesquisadores, chefes de departamento da Universidade Federal do Rio de Janeiro publicaram nota técnica de Nota técnica apontando ameaças de segurança hídrica no Rio (Agência Brasil, 2020b; Fonseca et al., 2020)

Vale ressaltar que a geomisna é resultante de ambientes aquáticos com excesso de nutrientes (fósforo e nitrogênio), especialmente em mananciais que recebem esgoto não tratado, que causam a eutrofização dos seus corpos d'água, diminuindo a concentração de oxigênio e desequilibrando todo ecossistema (fauna e flora) (Fonseca et al., 2020; Silva et al., 2019). A eutrofização colabora para a floração das algas e por consequência o surgimento de cianobactérias, com seu crescimento acelerado ocasionam o fenômeno "bloom" com aparecimento de manchas na superfície das águas, proporcionando às águas gosto e odor, devido aos compostos orgânicos naturais: o MIB (1,2,7,7-tetrametilbiciclo-[2.2.1] heptan-2-ol, ou simplesmente 2-metilisoborneol) SILVA et al., 2019e a GEOSMINA (Trans-1,10Dimetil-trans-9- decalol) (Silva et al., 2019, p.674675).

Recentemente o mundo está em restruturação sanitária, científica, econômica e social em decorrência dos impactos causados pela 
pandemia da COVID-19. Com isso, tornou-se necessário que os órgãos sanitários monitorem os casos e óbitos provenientes da disseminação desta patologia.

Muitos estudos científicos estão buscando relacionar a presença do vírus em corpos d'água e esgoto, os primeiros resultados foram divulgados na Holanda e nos Estados Unidos, a consagrada revista Nature apontou no início de abril que diversos grupos começaram analisar águas residuárias (Sodré et al., 2020, p.516).

A Ciência conseguiu evidenciar a relação da disseminação do vírus com a presença do mesmo no esgoto, portanto:

Os pesquisadores observaram que a contaminação do esgoto aconteceu antes do aumento exponencial da doença, enfatizando que o aumento da quantidade de material genético do SARS-CoV-2 no esgoto bruto possui relação com o número de mortes, tanto em relação à cidade de Paris quanto em todo território da França (Souza, et al., 2020, p.134).

Assim, Sodré et al. (2020, p.516) descrevem o desenvolvimento dos estudos:

A carga de partículas virais no esgoto pode ser medida ao se buscar motivos funcionais ou estruturais do vírus. Mesmo que, segundo a Organização Mundial de Saúde, a meia-vida de partículas viáveis de SARSCoV-2 em águas residuárias seja curta, provavelmente em função das condições adversas à manutenção de seu envelope viral lipídico, ainda não há estudos sobre a viabilidade de SARS-CoV-2 em esgotos. Mesmo assim, há diferentes estratégias para detecção de partículas viáveis e nãoviáveis que podem ser empregadas para se identificar a presença do vírus. Em termos de biossegurança, a transmissão entérica do SARS-CoV-2 é possível e pode representar em risco para a saúde de trabalhadores em estações de tratamento, caso não sejam seguidos os protocolos de higiene preconizados pela OMS e comumente usados para proteção geral por qualquer doença infecciosa, incluindo a COVID-19. Também há preocupação com a possibilidade de transmissão fecal-oral da COVID-19, especialmente em áreas com falta de saneamento, onde a capacidade de diagnóstico pode ser limitada (Sodré et al., 2020, p.516).

A COVID-19 não é transmissível pela ingestão da água, mas, a presença deste patógeno em corpos hídricos e/ou em redes de esgoto pode inferir dados da sua disseminação na população local.

A discussão em torno da qualidade das águas e do tratamento de esgoto no Brasil está aquecida ultimamente, de acordo com o Novo Marco do Saneamento Básico, Lei $\mathrm{n}^{\circ}$ 14.026, publicada em 15 de julho de 2020, possui o desafio de proporcionar até o ano de 2033: a universalização do acesso á água potável para 99\% da população e para $90 \%$ coleta e tratamento de esgoto. Estudos Instituto Trata Brasil (2021), pautados no SNIS (2019), apontam que, atualmente, $83,7 \%$ da população têm acesso à água tratada e a coleta/tratamento de esgoto $49,1 \%$. Portanto, o desafio é imenso, proporcionar infraestrutura sanitária a $16,3 \%$ dos brasileiros com água potável e para $45,9 \%$ a coleta e tratamento de esgoto.

\section{Conclusões}

O estudo demonstra a ausência de uma articulação conjunta entre a ANA - Agência Nacional de Águas, com as 60 outras agências reguladoras (estaduais e municipais), esta diversificação e descentralização da análise e controle da qualidade das águas no Brasil geram irresponsabilidades e até impunidades em casos de impactos ambientais e nos possíveis danos a saúde humana no consumo de água com cianobactérias e toxinas.

Cabe destacar os diversos episódios da presença de geosmina na água já tratada e disponibilizada para a população da cidade do Rio de Janeiro, onde a CEDAE reconheceu a presença da mesma na água, decorrente do impacto ambiental sofrido no Rio Guandu (excesso de nutrientes - fósforo e nitrogênio), geram a eutrofização, ou seja, o crescimento exponencial de algas que produzem a geosmina, esta por sua vez, proporciona sabor e odor à água. Portanto, este estudo sugestiona a unificação dos parâmetros da qualidade da água e do tratamento de esgoto no Brasil, a articulação e criação de um banco de dados nacional para alertas e prevenção a possíveis contaminações. 


\section{Agradecimentos}

Os autores agradecem à CAPES pela bolsa concedida.

\section{Referências}

Agência Brasil. 2020a. Pesquisadores mostram relação de água contaminada como zika vírus. Publicado em: 30 de março de 2020 às 05h32min. [online]. https://agenciabrasil.ebc.com.br/saude/noticia/ 2020-03/pesquisadores-mostram-relacao-daagua-contaminada-com-zika-virus.

Agência Brasil. 2020b. Nota técnica da UFRJ diz que há ameaça de segurança hídrica no Rio: estudo apontou lançamento de esgoto em afluentes do Rio Guandu. Publicado em 15 de março de 2020 às 23h. [online]. https://agenciabrasil.ebc.com.br/geral/noticia/2 020-01/nota-tecnica-da-ufrj-diz-que-haameaca-de-seguranca-hidrica-no-rio.

ANA - Agência Nacional das Águas. Agências Infranacionais, 2021.

[online].https://www.gov.br/ana/ptbr/assuntos/saneamento-basico/agenciasinfranacionais.

ANA - Agência Nacional das Águas. Portal da Qualidade das Águas, 2019. [online]. http://portalpnqa.ana.gov.br/default.aspx.

ARCE - Agência Reguladora do Estado do Ceará. Saneamento, 2021. [online].https://www.arce.ce.gov.br/coordenad orias/saneamento/\#: :text=A\%20Arce\%20atua \%20na\%20regula\%C3\%A7\%C3\%A3o,Lei\%2 014.394\%2C\%20de\%207\%20de.

Aslam, S.; Yousafzai, A.M. 2017. Chromium toxicity in fish: A review article. Journal of Entomology and Zoology Studies, 5 (3),p. 1483-1488. [online]. https://www.entomoljournal.com/archives/201 7/vol5issue3/PartU/5-3-168-230.pdf.

Assalie, J.L.S.; Machado, F.M. Panorama Setorial 2015-2018: Saneamento Básico, 2018. [online]. https://web.bndes.gov.br/bib/jspui/bitstream/14 08/17643/1/PRCapLIv212860_saneamento_co mpl_P.pdf.

Barreto, L.V. et al. 2013. Eutrofização em rios brasileiros. Enciclopédia Biosfera, Centro Científico Conhecer-Goiânia, 9(16), p. 2167. [online].

https://conhecer.org.br/ojs/index.php/biosfera/a rticle/view/3521.
Bifano, R.B.A. et al. 2020. Avaliação da Qualidade da Água em Microbacias Hidrográficas do Extremo Sul da Bahia, Brasil. Revista Brasileira de Geografia Física, 13(5), p. 24447-2461. [online].

DOI: https://doi.org/10.26848/rbgf.v13.5.p24472461

Braga, B. et al. 2005. Introdução à Engenharia Ambiental. 2. Ed. São Paulo: Pearson Prentice Hall.

Brasil. 2005. Resolução CONAMA 357, de 17 de março de 2005. Conselho Nacional de Meio Ambiente. [online]. http://conama.mma.gov.br/?option=com_sisco nama\&task=arquivo.download $\&$ id $=450$.

Brasil. 2020. Novo Marco de Saneamento é sancionado e garanteavançospara o País. 2020. Publicado em: 15 de julho de 2020 às 17h27min. [online].https://www.gov.br/ptbr/noticias/transito-etransportes/2020/07/novo-marco-desaneamento-e-sancionado-e-garante-avancospara-o-pais.

Brasil. 2011. Portaria $n^{\circ}$ 2.914, de 12 de dezembro de 2011. Dispõe sobre os procedimentos de controle e de vigilância da qualidade da água para consumo humano e seu padrão de potabilidade. [online]. https://bvsms.saude.gov.br/bvs/saudelegis/gm/ 2011/prt2914_12_12_2011.html.

CAESB - Companhia de Saneamento Ambiental do Distrito Federal. 2021a. Como a Água é Tratada. [online]. https://www.caesb.df.gov.br/como-a-agua-etratada.html.

CAESB - Companhia de Saneamento Ambiental do Distrito Federal. 2021b. Sistemas de Esgotamento. [online]. https://www.caesb.df.gov.br/esgoto/sistemasde-esgotamento.html.

CEDAE - Companhia Estadual de Águas e Esgotos do Rio de Janeiro. 2021a. A CEDAE. [online]. https://www.cedae.com.br/apresentacao.

CEDAE - Companhia Estadual de Águas e Esgotos do Rio de Janeiro.2021b. CEDAE adotará Plano de Contingência na ETA Guandu na noite deste sábado (06/02). Publicado em: 06 de fevereiro de 2021. [online].https://www.cedae.com.br/Noticias/de talhe/cedae-adotara-plano-de-contingencia-naeta-guandu-na-noite-deste-sabado-0602/id/786.

CETESB - Companhia Ambiental do Estado de São Paulo. 2017a. Qualidade das Águas 
Interiores no Estado de São Paulo - Apêndice D - Índices de Qualidade das Águas. [online]. https://cetesb.sp.gov.br/aguas-interiores/wpcontent/uploads/sites/12/2017/11/Ap\%C3\%AA ndice-D-\%C3\%8Dndices-de-Qualidade-das$\%$ C3\%81guas.pdf.

CETESB - Companhia Ambiental do Estado de São Paulo. 2017b.Qualidade das Águas Interiores no Estado de São Paulo - Apêndice E - Significado Ambiental e Sanitário das Variáveis de Qualidade. [online]. https://cetesb.sp.gov.br/aguas-interiores/wpcontent/uploads/sites/12/2017/11/Ap\%C3\%AA ndice-E-Significado-Ambiental-e-

Sanit\%C3\%A1 rio-das-Vari\%C3\%A1veis-deQualidade-2016.pdf.

CETESB - Companhia Ambiental do Estado de São Paulo. 2018. CETESB 50 Anos de Histórias \& Estórias. São Paulo. [online]. https://cetesb.sp.gov.br/wpcontent/uploads/2018/12/Livro-CETESB-50anos.pdf.

Chen, K. et al. 2020. Comparative analysis of surface water quality prediction performance and identification of key water parameters using different machine learning models based on big data, Water Research, 171, p. 115454. [online]. DOI: https://doi.org/10.1016/j.watres.2019.115454.

COSAMA -Companhia de Saneamento do Amazonas. A Cosama, 2021. http://www.cosama.am.gov.br/a-cosama/.

Costa, B.F.D.; Roche, K.F. 2020. Toxicidade aguda em área urbana da microbacia do córrego Água Boa (MS). Engenharia Sanitaria e Ambiental, 25(1), pp. 31-39. [online]. DOI: https://doi.org/10.1590/S141341522020147956.

Cullen, J.J. 1982. The deep Chlorophyll maximum: Comparing vertical profiles of chlorophyll a. Canadian Journal of Fisheries and Aquatic Sciences, 39, p.791-803.[online]. DOI: https://doi.org/10.1139/f82-108

Da Silva, et al. 2021. Gestão de recursos hídricos e manejo de bacias hidrográficas no Brasil: elementos básicos, histórico e estratégias. Revista Brasileira de Geografia Física, 14(03), 1626-1653. [online] DOI: https://doi.org/10.26848/rbgf.v14.3.p16261653

Da Silva Júnior, et al. 2020. IV-089-Mapeamento de Clorofila (Chl-a) no reservatório de Sobradinho-BA utilizando imagens Sentinel-
3/OLCI C2RCC, ABES- Associação Brasileira de Engenharia Sanitária e Ambiental, p. 1-8 p. 1-8.

Ewaid, S.H. et al. 2020. Development and evaluation of a water quality index for the Iraqi rivers. Hydrology, 7(3), p. 67. DOI: https://doi.org/10.3390/hydrology7030067

Feng, X. et al. 2018. Bioaccumulation of mercury in aquatic food chains. In: Biogeochemical Cycle of Mercury in Reservoir Systems in Wujiang River Basin, Southwest China (pp. 339-389). Springer, Singapore. [online]. DOI: https://doi.org/10.1007/978-981-10-6719-8_9

Figur, C.; Reis, J.T. 2017. A influência do uso e cobertura da terra nos parâmetros da qualidade da água na bacia hidrográfica do rio Abaúna, em Getúlio Vargas, RS. Ciência e Natura, 39(2), p. 352-365. [online]. DOI: https://doi.org/10.5902/2179460X24335

Fonseca, F.V. et al. 2020. Nota técnica da UFRJ sobre os problemas da qualidade da água que a população do Rio de Janeiro está vivenciando. Rio de Janeiro: UFRJ. Nota técnica n. 01. [online]. https://ufrj.br/sites/default/files/imgnoticia/2020/01/nota_tecnica_-

_caso_cedae.pdf.

Freeling, F. 2019. Occurrence and potential environmental risk of surfactants and their transformation products discharged by wastewater treatment plants. Science of The Total Environment, 681, 475-487. [online]. DOI:https://doi.org/10.1016/j.scitotenv.2019.0 4.445

Hong, Y. et al. 2020. Progress in the research of the toxicity effect mechanisms of heavy metals on freshwater organisms and their water quality criteria in China, Journal of Chemistry, Special Issue, $2020 . \quad$ [online]. DOI: https://doi.org/10.1155/2020/9010348

Human, L.R.D. et al. 2018. Natural nutrient enrichment and algal responses in near pristine micro-estuaries and micro-outlets. Science of the total environment, 624, p. 945954.[online].DOI:https://doi.org/10.1016/j.scit otenv.2017.12.184

Instituto Trata Brasil. 2021. Painel Saneamento Brasil. [online]. https://www.painelsaneamento.org.br/localidad e/index ?id $=0$.

Issii, T.M. et al. 2020. The role of legal protection in forest conservation in an urban matrix. Land Use Policy, 91, $104366 . \quad$ DOI: 
https://doi.org/10.1016/j.landusepol.2019.1043 66

Kim, J.; Kang, J. 2017. Toxic effects on bioaccumulation and hematological parameters of juvenile rockfish Sebastes schlegelii exposed to dietary lead $(\mathrm{Pb})$ and ascorbic acid. Chemosphere, 176, p. 131-140. [online]. DOI:https://doi.org/10.1016/j.chemosphere.20 17.02.097

Lamparelli, M.C. 2004. Graus de trofia em corpos d'água do estado de São Paulo: Avaliação dos métodos de monitoramento. Tese de Doutorado, Instituto de Biociências, Universidade de São Paulo. São Paulo. [online]. DOI: https://doi.org/10.11606/T.41.2004.tde20032006-075813

Li, X. et al. 2018. Distribution and diagenetic fate of synthetic surfactants and their metabolites in sewage-impacted estuarine sediments. Environmental pollution, 242, p. 209-218. [online].

DOI: https://doi.org/10.1016/j.envpol.2018.06.064

Lira, G.M. et al. 2020. Analysis of the Impact of Implementation of a Risk-Flood Retention Basin. International Journal of Advanced Engineering Research and Science, 7(1). DOI: https://doi.org/10.22161/ijaers.71.12

Lucon, T.N. et al. 2020. Cadmium behavior in a karst environment hydrological cycle. Environmental Science and Pollution Research, p. 1-15.[online]. DOI: https://doi.org/10.1007/s11356-020-07894-2

Luo, P. et al. 2020. Historical assessment and future sustainability challenges of Egyptian water resources management. Journal of Cleaner Production, 263, 121154. DOI: https://doi.org/10.1016/j.jclepro.2020.121154

Macias-Fauria, M. et al. 2020. Pleistocene Arctic megafaunal ecological engineering as a natural climate solution?. Philosophical Transactions of the Royal Society B, 375(1794), 20190122. DOI: https://doi.org/10.1098/rstb.2019.0122

Mckinley, D.C. et al. 2017. Citizen science can improve conservation science, natural resource management, and environmental protection. Biological Conservation, 208, p. 15-28.[online]. DOI: https://doi.org/10.1016/j.biocon.2016.05.01

Mendonça, J.K. A. et al. 2020. Rev. Sítio Novo, Palmas, 4(1), p. 53-61. DOI: http://dx.doi.org/10.47236/2594-

7036.2020.v4.i1.53-61p
Noulas, C. et al. 2018. Zinc in soils, water and food crops. Journal of Trace Elements in Medicine and Biology, 49, p. 252-260. [online]. DOI: https://doi.org/10.1016/j.jtemb.2018.02.009

Oliveira, C.S.P. et al. 2020. Análise de qualidade da água e percepção ambiental da Bacia Hidrográfica do Rio Pitimbu (BHRP). Revista Brasileira de Meio Ambiente, 8(3), p. 13-26. [online].

DOI: https://doi.org/10.5281/zenodo.3877633

Oliveira, D.G. et al. 2018. Land use and its impacts on the water quality of the Cachoeirinha Invernada Watershed, Guarulhos (SP).Revista Ambiente \& Água, 13(1). [online]. DOI:https://doi.org/10.4136/ambi-agua.2131

Oliveira, D.V.et al. 2017. Análise dos Parâmetros de Cromo e Hidrazina do Rio Itajaí Mirim da cidade de Brusque (SC) e seus efeitos na Saúde pelo consumo indireto dessas águas. RIES, 6(1), p.117-123. [online].DOI: https://doi.org/10.33362/ries.v6i1.1316

Pantano, G. et al. 2016. Sustentabilidade no Uso do Fósforo: Uma Questão de Segurança Hídrica e Alimentar. Quim. Nova, 39(6), p. 732-740. [online]. DOI: http://dx.doi.org/10.5935/01004042.20160086

Pantoja, D.N.S.M. et al. 2021. Avaliação dos parâmetros microbiológicos e físico-químicos de poços individuais no município de Barcarena/PA. Revista Ibero-Americana de Ciências Ambientais, 12(2). DOI: https://doi.org/10.6008/CBPC21796858.2021.002.0048

Passos, A.L.L. et al. 2018. Critério para Avaliação da Qualidade de Água no Brasil: Um Questionamento sobre os Parâmetros Utilizados. Fronteiras: Journal of Social, Techonological and Environmental Science, 7(2), p. 290-303. [online]. DOI: https://doi.org/10.21664/22388869.2018v7i2.p290-303

PNQA - Programa Nacional da Avaliação da Qualidade das Águas. 2021. O que é PNQA? [online].

http://pnqa.ana.gov.br/pnqa.aspx\#: :text=A\%2 0Ag\%C3\%AAncia\%20Nacional $\% 20 \mathrm{de} \% 20 \%$ C3\%81guas,campanhas\%20de $\% 20$ medi $\%$ C3\% A7\%C3\%A3o\%20de\%20vaz\%C3\%A3o.

Rajeshkumar, S.; Li, X. 2018. Bioaccumulation of heavy metals in fish species from the Meiliang Bay, Taihu Lake, China. Toxicology Reports, 5, p. 288-295.[online]. DOI: https://doi.org/10.1016/j.toxrep.2018.01.007 
Richter, C.A., Netto, J.M.A. 2007. Tratamento de Água: Tecnologia atualizada. 1. ed. São Paulo: Blucher.

Rocha, F.N.S. 2021. Influência da dinâmica de nutrientes para a eutrofização em corpos hídricos. Revista Multidisciplinar de Educação e Meio Ambiente, 2(2), 91. [online] DOI: https://doi.org/10.51189/rema/1660

Rodríguez-Tito, J., Gómez-Luna, L. 2020. Estado trófico de 24 embalses de agua en el oriente de Cuba. Revista Cubana De Química, 32(1), 135152. [online] https://cubanaquimica.uo.edu.cu/index.php/cq/ article/view/5131

SABESP - Companhia de Saneamento Básico do Estado de São Paulo. 2021a. Tratamento de água.

http://site.sabesp.com.br/site/interna/Default.as px?secaoId $=47$.

SABESP - Companhia de Saneamento Básico do Estado de São Paulo. 2021b. Tratamento de esgotos.

http://site.sabesp.com.br/site/interna/Default.as px?secaold $=49$.

SANEPAR - Companhia de Saneamento do Paraná. 2019. Perfil, 2019. [online]. http://site.sanepar.com.br/a-sanepar/perfil.

São Paulo. 1976. Decreto $\mathrm{N}^{\circ} 8.468$, de 08 de Setembro de 1976. (Atualizado com redação dada pelo Decreto 54.487, de 26 de Junho de 2009) - Aprova o Regulamento da Lei $\mathrm{n}^{\circ} 997$, de 31 de Maio de 1976, que dispõe sobre a prevenção e o controle da poluição do meio ambiente.

[online]. https://licenciamento.cetesb.sp.gov.br/legislaca o/estadual/decretos/1976_Dec_Est_8468.pdf.

Serbeto, L.F., et al. 2021. Determinação da Concentração de Clorofila-a por Sensoriamento Remoto no Reservatório de Chapéu d'Úvas $(\mathrm{Mg})$, Brasil, Revista Brasileira de Geografia Física, 14(6), p.3561-3576. [online]. DOI: https://doi.org/10.26848/rbgf.v14.6.p35833598

Silva, G.S.P. et al. 2019. Remoção dos Compostos MIB e Geosmina de Abastecimento Usando Carvão Ativado de Caroço de Pêssego. Rev. Virtual Quim., 11(3), p. 673-685. [online]. DOI: http://dx.doi.org/10.21577/19846835.20190050

Silva, M.A.; Araújo, R.R. 2017. Análise temporal da qualidade da água no córrego limoeiro e no rio Pirapozinho no Estado de São Paulo - Brasil.
Formação 1(24). [online]. DOI: https://doi.org/10.33081/formacao.v1i24.4656

Silva, M.A.D. et al. 2020. Sobreposição de riscos e impactos no desastre da Vale emBrumadinho. Ciência e Cultura, 72(2), 21-28. DOI: https://doi.org/10.21800/231766602020000200008

Singh, T. et al. 2020. An effective approach for the degradation of phenolic waste: phenols and cresols. In: Abatement of Environmental Pollutants, p. 203-243. [online]. DOI: https://doi.org/10.1016/B978-0-12-8180952.00011-4

Smiderle, J. et al.2020. Crise na Cedae: como chegou até aqui? Conjuntura Econômica - FGV, p.34-37. [online]. Disponível em: https://ceri.fgv.br/sites/default/files/202003/conjunturaeconomica_crise_na_cedae.pdf. Acesso em: 05 abr. 2021.

Sodré, F.F. et al. 2020. Epidemiologia do Esgoto como estratégia para monitoramento comunitário, mapeamento de focos emergentes e elaboração de sistemas de alerta rápido para COVID-19. Quim. Nova, 43(4), p.515-519. [online]. DOI: http://dx.doi.org/10.21577/01004042.20170545

Souza, L.P.S. et al. 2020. Presença do novo coronavírus (SARS-CoV-2) nos esgotos sanitários: apontamentos para ações complementares de vigilância à saúde em tempos de pandemia.Vigil. Sanit. Debate, 8 (3), p.132-138. [online]. DOI: https://doi.org/10.22239/2317-269x.01624.

Ulgenes, Y. et al. 2020. Modeling water quality for seawater aquaculture. In Fish Farming Technology, pp. 383-388. CRC Press. [online]. https://www.taylorfrancis.com/chapters/edit/10 .1201/9781003077770-62/modeling-waterquality-seawater-aquaculture-ulgenes-selandlunde

Xiang, X. et al. 2021. Urban water resource management for sustainable environment planning using artificial intelligence techniques. Environmental Impact Assessment Review, 86, 106515.

DOI: https://doi.org/10.1016/j.eiar.2020.106515

Wei, X. et al. 2016. Characterization of phenol and cresol biodegradation by compound-specific stable isotope analysis. Environmental Pollution, 210, p. 166-173. [online]. DOI: https://doi.org/10.1016/j.envpol.2015.11.005 